\title{
SUBJECTIVE VERSUS OBJECTIVE STRESS IN NONCRITICALLY ILL HOSPITALIZED AND OUTPATIENT ADULT MEN
}

Francisco J. Karkow, Wilson P. Spiandorello, Rossane F. Godoy, Patricia Pezzi, Antônio G. M. Karkow and Joel Faintuch

KARKOW FJ et al. Subjective versus objective stress in noncritically ill hospitalized and outpatient adult men. Rev. Hosp. Clín. Fac. Med. S. Paulo 59(4):161-167, 2004.

A cross-sectional study of 120 subjects was performed with the purpose of evaluating stress hormones and emotional stress (anxiety) in outpatient and hospitalized subjects. The aims were to determine the degree of objective stress, as well as to correlate this finding with subjective findings, estimated using Beck's Anxiety Inventory..

METHOD: Three populations were investigated, namely outpatient clinical cases (Group I, n = 30), hospitalized clinical individuals (Group II, $\mathrm{n}=30$ ), and hospitalized surgical candidates (Group III, $\mathrm{n}=30$ ). Controls (Group IV, $\mathrm{n}=30$ ) were healthy volunteers who were health-care professionals and students. To avoid hormone interactions, only men were enrolled in all groups. All hospitalized subjects were tested on admission and before therapeutic interventions. Fasting epinephrine, norepinephrine, and cortisol were measured in the morning, and Beck's Anxiety Inventory was adminstered by a trained psychologist.

RESULTS: The 3 patient groups displayed higher anxiety levels than the controls. Hormone concentrations did not present remarkable changes and did not correlate with subjective stress (anxiety).

CONCLUSIONS: 1) Subjective disorders (as determined with Beck's Anxiety Inventory ) were a common finding in both outpatient and hospitalized populations, without differences between the various groups; 2) Objective stress (as determined by elevated hormone levels) was more difficult to confirm-findings rarely exceeded the reference range; 3) Correlation between the two variables could not be demonstrated; 4) Further studies are necessary to define stress quantification and interpretation in patient populations, especially in relationship with nutritional diagnosis and dietetic prescription.

KEY WORDS: Stress. Metabolic stress. Anxiety. Epinephrine. Norepinephrine. Cortisol.

The concept of stress has slowly crystallized during the last century into a complex theory that unifies physical, neurogenic, and disease-related stress. The theory of stress encompasses hormone responses, sympathetic and parasympathetic reflexes, emotional changes, hemodynamic adjustments, and metabolic consequences. In its phylogenetic origin, stress has been accepted as a natural defense mechanism for ordinary emergency situations, promoting muscle strength, mental acuity, and substrate mobilization; however, its role in critical illness, especially as persistent stress, may be less beneficial or frankly deleterious. ${ }^{1}$

About 70 years ago Selye and Collip ${ }^{2}$ were among the first to describe a pattern of physiologic, meta-

From the University of Caxias do Sul Caxias do Sul/RS and Hospital das Clínicas, Faculty of Medicine, University of São Paulo - São Paulo/SP, Brazil.

E-mail: rnyounes@yahoo.com Received for publication on October 8, 2003. bolic, and histologic reactions of the organism when challenged by strong sensorial and psychologic stimuli. Within the ensuing decades, a large cast of stress triggers was unveiled, including heat, cold, fear, anxiety, panic, trauma, surgery, sepsis, and other types of organic or mental aggression. ${ }^{3-7}$

At the same time that Selye and others were interested in the endocrinologic and neurophysiologic consequences of stress in physically healthy subjects, ${ }^{2}$ Cuthbertson was unknowingly investigating the same 
general question, but from the point of view of nutritional and metabolic repercussions after severe injury. ${ }^{8}$ It was the subsequent initiative of Moore that brought together the various angles of this polygon for hospitalized patients. His description of the metabolic response to surgical trauma proved to be a paradigm for countless other situations in internal medicine, endocrinology, neurology, pediatrics, trauma, orthopedics, and intensive care medicine. ${ }^{9}$

In the field of clinical nutrition, Cuthbertson's and Moore's pioneering contributions were deemed more valuable and are more frequently cited than those of Selye and others, especially after the advent of modern nutritional assessment and support. The reason is quite obvious: stressed patients require a greater quantity and more-specialized energy substrates than conventional patients because they are more likely to be malnourished and tend to respond poorly or not at all to dietetic replenishment. Therefore, they represent a high-risk group that imposes considerable demands on the resources of the nutritional team and thus deserve more careful attention. ${ }^{10}$

Such theoretic principles have been embodied in daily practice both in the form of nutritional questionnaires such as the Global Subjective Assessment of Detsky et al. , ${ }^{11}$ for which stress is an important parameter, and in equations for calorie prescriptions derived from the studies of Long et al. and others, in which a stress index is typically incorporated. ${ }^{12}$

Although it is implicit that any experienced professional can clinically recognize and quantitate metabolic stress when facing it without the need for biochemical measurements, the overlap of emotional and physical stress may create interpretative conflicts. Few studies have attempted to separate the two components, namely anxiety and mental disturbance from one side, and tissue damage and contraregulatory hormone response from the other.

It might be argued that differentiating between emotional and physical stress is an irrelevant detail, since both situations may be followed by similar peaks of cortisol and catecholamines, creating an equivalent contraregulatory environment. ${ }^{3-7}$ In fact, multiple other mechanisms and mediators may be involved in surgical and septic hypermetabolism and protein catabolism. Individual responses are so varied that even the best calculations occasionally miss the point, rendering it necessary to employ indirect calorimetry, nitrogen balance, and other cumbersome diagnostic tools. ${ }^{13}$

It is currently recommended that all hospitalized patients undergo nutritional assessment. Between 30\% and $50 \%$ of hospitalized patients will display signs of protein-energy malnutrition, and as many as $15 \%$ will be selected for some form of nutritional support. ${ }^{14}$ Stress and anxiety evaluation are indirect but relevant tools in this process, both for diagnosis and dietetic prescription. ${ }^{11,12}$ As a consequence, stress and anxiety may have a major impact on the indication, duration, and energy input during nutritional therapy, and therefore on financial disbursements for diets and other treatments, as well as on total costs of hospitalization. ${ }^{14}$

Given the scarcity of simultaneous objective and subjective assessment of stress or stress-related symptoms in hospital populations, a clinical protocol was designed, aiming to determine the patterns and correlations of the two phenomena.

\section{METHOD}

The study was approved by the Ethical Committee of the University of Caxias do Sul on April 10, 2002 Sub- jects $(n=120$, age $37.5 \pm 14.0)$ entered the study after informed consent. To mimick a situation of routine nutritional evaluation and prescription, all procedures were done within the first 3 days after enrollment before any clinical or surgical intervention.

Three test groups of 30 men who were treated at the General Hospital of the University of Caxias do Sul, Brazil, were formed: outpatient clinical subjects (Group I), hospitalized clinical patients (Group II), and hospitalized surgical patients (Group III).

Additionally 30 controls (Group IV) were recruited among students and employees of the University. So these controls would approximately match the other populations, they were not individually paired to any patient but were selected according to the observed distribution of age and body mass.

No randomization was adopted; instead, the first 30 subjects in each category who fulfilled the criteria for inclusion and exclusion were enrolled. To minimize potential interference of female sexual cycles, only males were enrolled.

The total duration of the study was 10 months (40 weeks), with an accrual of about 3 cases/week, despite the fact that both the outpatient service and the hospitalization unit are quite busy and receive 10 to 15 new patients/ week. The unhurried pace can be explained by the need for carefully considering inclusion and exclusion criteria, as well as by the fact that a single psychologist performed all tests to ensure uniform quality and reliability of the results.

Criteria of inclusion: males aged 18 to 70 ; free from pituitary or adrenal disease, cachexia, or morbid obesity; elective hospital registration and/ or admission; informed consent.

Criteria of exclusion: shock, sepsis, coma, critical disease; continuous therapy with hormones, vasocons- 
trictors or dilators, beta-blockers, calcium-channel blockers, bronchial dilators or neuro-psychiatric drugs (medications for pain were permitted); alcohol or substance abuse; psychiatric disease; major surgery or hospitalization in the last 30 days; failure to understand or comply with the protocol.

\section{Demographics}

The mean ages of the groups (years) were $37.5 \pm 14.0$ (Group I), 48.6 \pm 17.2 (Group II), $46.3 \pm 14.3$ (Group III) and $35.3 \pm 13.1$ (Group IV- controls). There was a small but significant difference between the controls and Groups II and III $(P<.05)$. The principal diagnoses are shown in table I.

\section{Method}

The classic plasma stress hormones epinephrine, norepinephrine, and cortisol were measured, and Beck's Anxiety Inventory (BAI) was administered. ${ }^{15}$ Subjects had to refrain from alcohol, smoking, drugs mentioned in the exclusion criteria, and consumption of stimulant foods and drinks (cof- fee, tea, cola beverages, chocolate, bananas, and nuts) for 72 hours prior to testing.

Fasting hormone levels were measured at 8:00 AM and were processed by HPLC $^{16}$

(epinephrine and norepinephrine) or by chemoluminescence (cortisol) in a specialized laboratory.

The entire BAI was administerd by a trained psychologist on the same day whenever the person reported he was comfortable and relaxed. The translated and validated Portuguese version was used, and scores of anxiety were interpreted as minimal or normal $(0$ - 10), slight (11- 20), moderate $(21-30)$, or severe $(>31) .{ }^{17}$

Statistical methods: Findings are presented as mean $\pm \mathrm{SD}$. Differences between the groups were investigated by analysis of variance and post-hoc Scheffe test when normal distribution was present, or by Kruskall-Wallis and Mann-Whitney nonparametric analysis when numbers did not pass Levene's test. Results were also examined by Pearson linear correlation. Significance was established at $P<.05$ ( $a=5 \%, b=20 \%$ ).

Table 1 - Clinical features of the population.

\begin{tabular}{lccc}
\hline Diagnosis & Group I & Group II & Group III \\
\hline General gastrointestinal diseases & $46.2 \%$ & & \\
Pulmonary conditions & $29.7 \%$ & $23.1 \%$ & \\
Cardiocirculatory disorders & & $49.5 \%$ & \\
Chronic malnutrition & $10.6 \%$ & $26.4 \%$ & \\
Osteoarthiculary disorders & & & $36.3 \%$ \\
Chronic colelithiasis & & & $26.4 \%$ \\
Cancer of the digestive tract & & $29.7 \%$ \\
Abdominal hernias & $13.2 \%$ & $6.6 \%$ \\
Other situations & & \\
\hline
\end{tabular}

Note: Subjects in Group IV denied having any acute or chronic disorders.

Table 2 - Beck’s Anxiety Inventory.

\begin{tabular}{lcccc}
\hline Groups & I & II & III & IV \\
\hline \multirow{2}{*}{ Differences $(P)$} & $25.3 \pm 12.1$ & $26.6 \pm 11.5$ & $24.5 \pm 10.9$ & $7.2 \pm 6.3$ \\
& II: 0.70 & III: 0.89 & IV: $<.001^{*}$ & I: $<.001 *$ \\
\hline
\end{tabular}

Absolute values are given, along with differences between the groups. * Statistically significant 
Table 3 - Stress hormones: concentrations.

\begin{tabular}{lcccc}
\hline Groups & I & II & III & IV \\
\hline Epinephrine $(\mathrm{pg} / \mathrm{mL})$ & $56.7 \pm 39.6$ & $46.9 \pm 43.66$ & $0.7 \pm 37.5$ & $73.5 \pm 41.5$ \\
Norepinephrine(pg/mL) & $296.5 \pm 157.9$ & $274.1 \pm 191.5$ & $302.5 \pm 259.8$ & $306.9 \pm 256.3$ \\
Cortisol $(\mathrm{ug} / \mathrm{mL})$ & $18.3 \pm 7.2$ & $19.5 \pm 9.5$ & $25.4 \pm 10.7$ & $19.7 \pm 6.9$ \\
\hline
\end{tabular}

Table 4 - Differences between findings of stress hormones (shown as the $P$ value).

\begin{tabular}{lccc}
\hline Groups & Epinephrine & Norepinephrine & Cortisol \\
\hline I X II & .17 & .70 & .48 \\
I X III & .62 & .59 & $.001^{*}$ \\
I X IV & .10 & .84 & .43 \\
II X III & $.04 *$ & .88 & $.02 *$ \\
II X IV & $.01^{*}$ & .24 & .86 \\
III X IV & .20 & .44 & $.03 *$ \\
\hline
\end{tabular}

Note: Differences were considered significant whenever $P<.05$. $*$ Statistically significant
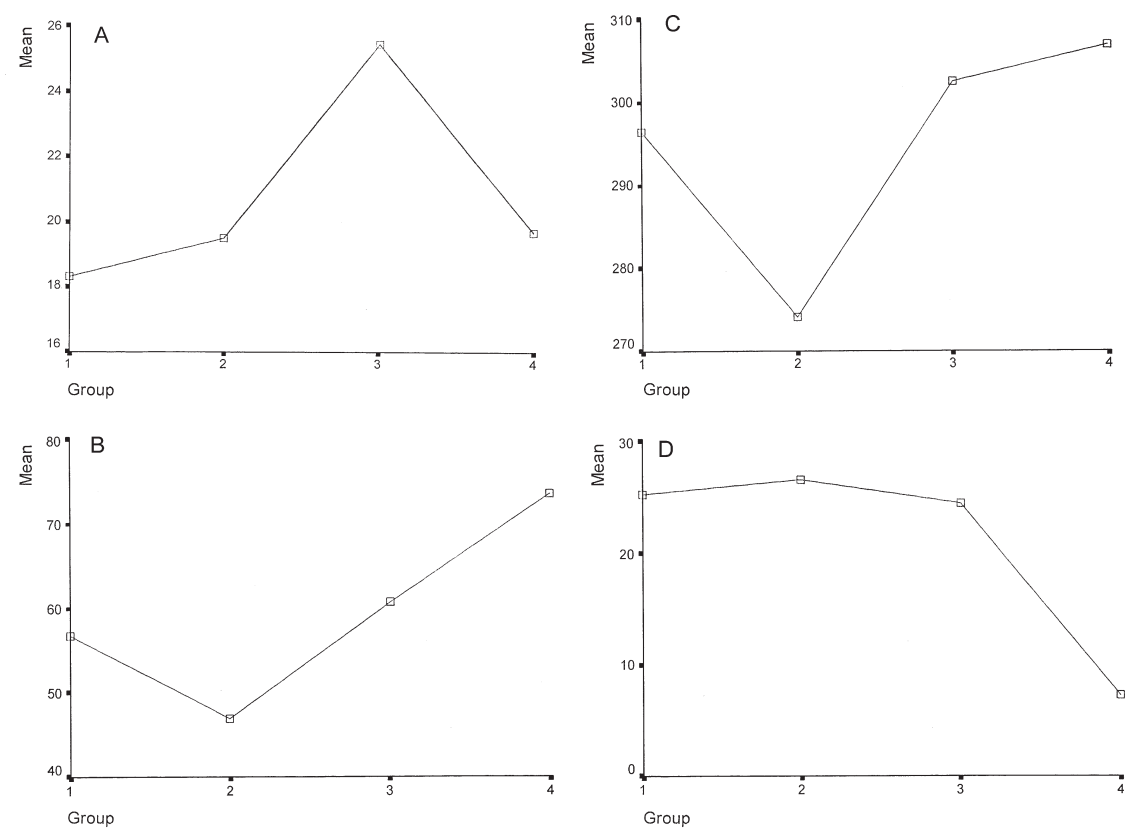

Figure 1 - Hormones and anxiety in the 4 populations. A - Cortisol; B - Epinephrine; C - Norepinephrine; D - Beck's questionnaire

Table 5 - Pearson linear regression analysis.

\begin{tabular}{lcccc}
\hline Variables & BAI & Epi & Norepi & Cortisol \\
\hline BAI & 1.000 & -0.045 & 0.010 & 0.083 \\
Epinephrine & -0.045 & 1.000 & 0.132 & -0.117 \\
Norepinephrine & 0.010 & 0.132 & 1.000 & -0.001 \\
Cortisol & 0.083 & -0.117 & -0.001 & 1.000 \\
\hline
\end{tabular}

Values are shown as Pearson's $r$ index; None of them were significant. norepinephrine $(r=0.132 ; P=.075)$, which is rather expected for the two adrenergic agents.

\section{DISCUSSION}

In the classic model of neuroendocrine response to stress, the hypothalamus receives information in the form of neural and humoral signals, thereafter activating the pituitary gland. A cascade of hormonal interactions from pituitary, adrenals, endocrine pancreas, and eventually thyroid and sexual glands follows in concert with sympathetic and parasympathetic phenomena. Various metabolic and nutritional impacts can be observed when serious injury is involved, with emphasis on water and sodium retention, potassium excretion, glucose intolerance, hyperglycemia, protein catabolism, and immune deficiency. ${ }^{3,4,9,18}$

In recent decades, this picture has been further crowded by the identification of scores of other biologic and immunologic mediators. These predominantly include cytokines, but also chemokines, eicosanoids, opioids, acute phase proteins, coagulation factors, plasma complement fractions, and many others that may interact with or somehow modify expected responses. ${ }^{19-21}$ All these advances notwithstanding, traditional stress hormones are still the yardstick for estimating physical and mental aggression. ${ }^{4,5,7,20-22}$

Cortisol is a sensitive marker for somatic and emotional aggression, because it is responsible for an increase in the secretion of catecholamines. This has been repeatedly highlighted not only in trauma, sepsis, surgery, and 
general anesthesia, but also in anxiety, fear, and panic..$^{20-25}$

In the present series, levels almost never exceeded the normal range, but one distinct pattern was revealed, specifically in surgical candidates. Differently from other populations, their baseline cortisol findings tended to be elevated, as shown in Tables 3 and 4. Cortisol is conventionally classified as a nonspecific marker of stress; therefore, it should be affected by other clinical situations as well. However, under the conditions of this study, only the presence of surgical disease was sufficient to induce a noticeable change in plasma concentrations.

As mentioned in the Methods section, these patients were marginally older than those in Groups I and IV, but it is unlikely that age played any role in the findings, since cases in Group II were older as well and exhibited a conventional hormonal pattern. In addition to quantitative considerations, it may be speculated that some degreee of stressor specificity influences the neuroendocrine response, as advocated by certain authors. ${ }^{25,26}$

Catecholamine measurements were not advantageous in the current circumstances. Norepinephrine did not present any unusual pattern when the groups were compared, and the single divergent behavior of epinephrine was negative, indicating a diminished reaction of hospitalized patients with clinical problems (Group II), which cannot be easily explained.

Such findings do not coincide with those of other teams that report rather parallel activation and equivalent clinical profile of catecholamines and corticosteroids, both in nonope$\operatorname{rated}^{4,5,24,27}$ and in surgical populations. ${ }^{3,7,10,20,22,25,28}$ The fact that only recently admitted subjects who had not yet undergone any diagnostic or therapeutic intervention and were free from acute disease or discomfort were included in the current protocol cer- tainly supports the lack of abnormalities. As already mentioned, measurements did not cross the limits of the reference range.

Recent investigations suggest that at least in mentally stressed populations, baseline findings may not be representative of later results. In adolescents experimentally undergoing psychological stress, no change in catecholamine, cortisol, growth hormone, or testosterone concentrations was registered at the beginning of the test, despite the presence of anxiety disorder in that population. Only 30 minutes after the end of the procedure did epinephrine, growth hormone, and testosterone significally change. ${ }^{29}$

The most reliable marker of stress in this protocol was BAI, which consistently distinguished sick populations from control subjects (Tables 3 and 4, Figure 1). BAI is not a routine method for diagnosis of stress in general clinical and surgical populations, and when employed by others, typically after more severe aggressions, appeared to be less valuable that biochemical determinations. ${ }^{3,4,7,22-25,28,29}$

Only occasional groups identified anxiety as the primary phenomenon of stress, which was subsequently followed by neurohormonal alterations. ${ }^{30,31}$ However, examples of good correlation between anxiety measured in association with other variables and stress in various populations can be found in the recent literature..$^{32,33}$

Subjective global assessment ${ }^{11}$ and Long's equation ${ }^{12}$ were not included in the objectives of this investigation; therefore, nothing can be affirmed regarding their association with results of emotional and physical stress measurements as here defined. Nevertheless, it is improbable that good correlation with hormone levels would be demonstrated, since these concentrations remained fundamentally normal and rarely distinguished ill from healthy groups.

It is likely that BAI scores would more frequently coincide with a clinical judgment of stress, since they sharply discriminated patients from controls. Still it should be remarked that the enrolled groups were heterogenous, with basic conditions ranging from uncomplicated hernia and peptic ulcer disease to fairly advanced cardiopulmonary disorders and cancer. In spite of this heterogenecity, BAI findings for Groups I, II, and III were not significantly different (Table 2, Figure 1).

Consequently, at the same time that the current model answers a few questions, fresh ones are raised: What are the exact dimensions and implications of stress in noncritical hospital patients? How relevant are they for results of the nutritional assessment? What are the repercussions for expenses with nutritional therapy and total hospitalization costs? And what is the ideal diagnostic procedure?

Further studies aiming at more detailed documentation of the natural history of stress in conventional outpatient and hospitalized populations will be required. Comparison of psychological tests such as BAI with other markers, especially for protein catabolism, insulin resistance, gluconeogenesis, nutritional replenishment, and notably clinical stress indices is a priority for unveiling their possible role in hospital practice.

One could speculate that although very much has been published during the last century about the contrast between uncomplicated fasting versus stressed starvation, the need has not been entirely fulfilled for tools for stress measurement that are appropriate for routine nutritional assessment and prescription of general clinical and surgical patients. ${ }^{30}$

\section{CONCLUSIONS}

It is concluded that:

1) Subjective stress (as measured 
with BAI) was a common finding in both outpatient and hospitalized populations, without differences between the various groups; 2) Objective stress (as indicated by elevated hor- mones) was more difficult to confirm, with findings rarely exceeding the reference range; 3) Correlation between the two variables could not be demonstrated; 4) Further studies are necessary to define stress quantification in patient populations, especially as it relates to nutritional diagnosis and dietetic prescription.

\section{RESUMO}

KARKOW FJ e col. Estresse subjetivo versus objetivo em homens não criticamente enfermos ambulatoriais e hospitalizados. Rev Hosp Clin Fac Med S Paulo 59(4):161167, 2004.

Um estudo transversal de 120 indivíduos foi executado visando avaliar hormônios do estresse e estresse subjetivo (ansiedade) em casos ambulatoriais e hospitalizados. O objetivo era determinar o grau de estresse objetivo, bem como correlacionar este achado com queixas subjetivas, estimadas pelo Inventário de Ansiedade de Beck.

MÉTODO: Três populações foram investigadas, nominalmente doentes clínicos ambulatoriais (Grupo I, n= 30), enfermos clínicos hospitalizados
(Grupo II, n=30), e pacientes cirúrgicos hospitalizados (Grupo III, n= 30). Os controles (Grupo IV, $n=30$ ) eram voluntários sadios recrutados entre profissionais da saúde e estudantes. Todos casos hospitalizados foram documentados na admissão, antes de quaisquer procedimentos terapêuticos, e somente homens foram selecionados em todos os grupos, a fim de contornar interações hormonais. A adrenalina, noradrenalina e cortisol foram mensurados pela manhã, e o Inventário de Ansiedade de Beck foi aplicado por uma psicóloga especializada.

RESULTADOS: Os três grupos de doentes exibiram níveis de ansiedade superiores aos dos controles. As taxas hormonais não estavam apreciavelmente alteradas, e não se corelacionaram com os achados de estresse subjetivo (ansiedade).

CONCLUSÕES: 1) Anormalidades subjetivas (Inventário de Ansiedade de Beck ) foram comuns tanto em populações internadas quanto ambulatoriais, sem diferenças entre os grupos; 2) Estresse objetivo (hormonal) foi mais difícil de confirmar e os valores raramente ultrapassaram a faixa de referência; 3) Não se conseguiu demonstrar correlação entre as duas órdens de variáveis; 4) Estudos adicionais são necessários para definir a quantificação e a interpretação de estresse em populações enfermas, especialmente para fins de diagnóstico nutricional e prescrição dietética;

UNITERMOS: Estresse. Estresse metabólico. Ansiedade. Adrenalina. Noradrenalina. Cortisol.

\section{REFERENCES}

1. Wilmore DW, Long JM, Mason AD, Pruitt BA Jr. Stress in surgical patients as a neurophysiologic reflex response. Surg Gynecol Obstet 1976;138:142-257.

2. Selye H, Collip, JB. Fundamental factors in the interpretations of stimuli influencing endocrine glands. Endocrinology 1936;20:667-72.

3. Halter JB, Pflug AE, Porte D. Mechanism of plasma catecholamine increases during surgical stress in men. J Clin Metab 1977;45:936.

4. Morgan CA 3rd, Wang S, Mason J, Southwick SM, Fox P, Hazlett $\mathrm{G}$, et al. Hormone profiles in humans experiencing military survival training. Biol Psychiatry 2000;47:891-901.

5. Brenner IM, Zamechi K, Shek PN. The impact of heat exposure and repeated exercise on circulating stress hormones. Eur J App Physiol 1997;76 445-54.
6. American Psychiatric Association. Diagnostic and statistical manual of mental disorders. Fourth ed, DSM-IV. Washington, D.C. American Psychiatric Association, 1994.

7. Hetz W, Kamp HD, Zimmermann U, von Bohlen A, Wildt L, Schuettler J. Stress hormones in accident patients studied before admission to hospital. J Accid Emerg Med 1996;13:243-7.

8. Cuthbertson DP - The disturbance of metabolism poduced by bony and non-bony injury with notes on certain abnormal conditions of bone. Biochem J 1930;24:1244-63.

9. Moore FD. Metabolic care of the surgical patient, Philadelphia, Saunders, 1959.

10. Richards JR. Metabolic response to injury, infection and starvation. In Richards Jr \& Kinney Jm (eds), Nutritional aspects of care in the critically ill, Edinburgh, Churchill Livingstone, 1977, pp 273-302. 
11. Detsky AS, McLaughlin JR, Baker JP, Johnston N, Whittaker S, Mendelson RA, et al. What is subjective global assessment of nutritional status ? JPEN J Parent Ent Nutr 1987;11:8-13.

12. Long CL, Schaffel N, Geiger JW, Schiller WR, Blakemore WS. Metabolic response to injury and illness: estimation of energy and protein needs from indirect calorimetry and nitrogen balance. JPEN J Parent Ent Nutr 1979;3:452-56.

13. Faintuch J. Nutritional abnormalities in inflammatory bowel disease. Rev Hosp Clin Fac Med S Paulo 2002;57:129-33.

14. Bernstein LH, Shaw-Stiffel TA, Schorow M, Brouillette R. Financial implications of malnutrition. Clin Lab Med 1993;13:491-507.

15. Beck AT, Epstein N, Brown G, Steer RA. An inventory for measuring clinical anxiety: Psychometric properties. J Consult Clin Psychol 1988;56:893-97.

16. Kumarathasan P, Vincent R. New approach to the simultaneous analysis of catecholamines and tyrosines in biological fluids. $\mathbf{J}$ Chromatograph Analysis 2003;987: 349-58.

17. Cunha JA. Manual da versão em Português das escalas de Beck. São Paulo, Editora Casa do Psicólogo, 2001, pp 11-13.

18. Vermes I, Beishuizen A. The hypothalamic-pituitary-adrenal response to critical illness. Best Pract Res Clin Endocrinol Metab 2001;15:495-511.

19. Faintuch J. Nutritional support in the critical patient. In Felix VN (ed): Update in Intensive Care Medicine, Vol 1,São Paulo, Brazil, Sopati, 1997, pp 17-18

20. Saito T, Tazawa K, Yokoyama Y, Saito M. Surgical stress inhibits the growth of fibroblasts through the elevation of plasma cathecolamine and cortisol concentrations. Surg Today 1997; 7:627-31.

21. Michelson D, Gold PW, Sternberg EM. The stress response in critical illness. New Horiz 1994;2:426-31.

22. Chae BK, Lee HW, Sun K, Choi YH, Kim HM. The effect of combined epidural and light general anesthesia on stress hormones in open heart surgery patients. Surg Today $1998 ; 28: 727-31$
23. Fukuda S, Morimoto K, Mure K, Maruyama S. Effect of the Hanshin-Awaji earthquake on posttraumatic stress, lifestyle changes and cortisol levels of victims. Arch Environ Health $2000 \cdot 55: 121-5$

24. Skosnik PD, Chatterton RT Jr, Swisher T, Park S. Modulation of attentional inhibition by norepinephrine and cortisol after psychological stress. Int J Psychophisiol, 2000;36:59-68.

25. Friedrich M, Rixecker D, Friedrich G. Evaluation of stress-related hormones after surgery. Clin Exp Obst \& Gyn 1999;2:71-5.

26. Pacak K, Palkovits M. Stressor specificity of central neuroendocrine responses: implications for stress-related disorders. Endocr Rev 2001;22:502-48.

27. Kloppenborg PWC. Adrenocorticol function: an indicator of severity of disease and survival in chronic critically ill patients. Intensive Care Med 1992;18:93-96.

28. Wurtman RJ. Stress and the adrenocortical control of epinephrine synthesis. Metabolism 2002;51(6 Suppl 1):11-4.

29. Gerra G, Zaimovic A, Zambelli U, Timpano M, Reali N, Bernasconi S, et al. Neuroendocrine responses to psychological stress in adolescents with anxiety disorder Neuropsychobiology J 2000;42:82-92.

30. Boudarene M, Legros JJ, Timsit-Berthier M. Etude de la réponse de stress: rôle de l'anxiéte, du cortisol et du DHEAs. Encephale 2002; 28:139-46.

31. Noble RE. Diagnosis of stress. Metabolism 2002;51(6 Suppl 1):379.

32. Boye B, Malt UF. Stress response symptoms in relatives of acutely admitted psychotic patients: a pilot study. Nord J Psychiatry 2002;56:253-60.

33. Huckabay LM, Tilem-Kessler D. Patterns of parental stress in PICU emergency admission. Dimens Crit Care Nurs 1999; 18:36-42. 